\title{
Investigations into Morphology and Mechanical Properties of Epoxidized Polystyrene/Polybutadiene/Polystyrene (SBS) Triblock Copolymer
}

\author{
Rajesh Pandit ${ }^{1,2}$, BoulosYoussef ${ }^{3}$, Jean Marc Saiter ${ }^{3}$, Rameshwar Adhikari ${ }^{\text {1* }}$ \\ ${ }^{1}$ Central Department of Chemistry, Tribhuvan University, Kirtipur, Kathmandu, Nepal, ${ }^{2}$ Department of \\ Chemistry, Tri-Chandra Campus, Tribhuvan University, Kathmandu, Nepal, ${ }^{3}$ Laboratory LECAP, \\ Institut des Materiaux de Rouen, Universite de Rouen, Saint Etienne du Rouvray Cedex, France, \\ E-mail:nepalpolymer@yahoo.com
}

\begin{abstract}
An architecturally asymmetric polystyrene-block-polybutadiene-block-polystyrene (SBS) triblock copolymer possessing lamellar morphology was subjected to different degrees of epoxidation with performic acid generated in situ by the reaction between hydrogen peroxide and formic acid. The effect of the chemical modification on morphology and mechanical behaviour of the block copolymer was investigated by means of different techniques such as electron microscopy, Fourier transform Infrared (FTIR) spectroscopy, tensile testing and differential scanning calorimetry (DSC). It was found that the microphase separation behaviour and hence the mechanical properties of the materials can be drastically altered via epoxidation of the diene block of the styrene/diene triblock copolymers.
\end{abstract}

Keywords: Block copolymer, Epoxidation, FTIR spectroscopy, Electron microscopy, Mechanical properties

\section{Introduction}

Block Copolymer molecules self-assemble in the melt as well as in the solid state into a large variety of periodic nanostructures through intramolecular phase separation. The morphologies of the block copolymer may vary from body centered cube (BCC), hexagonal (Hex) cylinders, co-continuous gyroid (G) to lamellar (L) structures that are controlled by the molecular weight, segment size, Flory-Huggins segmental interaction parameter $(\chi)$, degree of polymerization $(\mathrm{N})$, volume fraction of constituent block $\left(f_{a}\right)$ and molecular architecture ${ }^{1,2}$. The periodicity of these structures lies between the 10-100 nm which enables precise control of their mechanical properties over the wide range ${ }^{1-4}$.

Polystyrene-block-polybutadiene-block-polystyrene (SBS) and Polystyrene-block-polyisopreneblock-polystyrene (SIS) triblock copolymers are the thermoplastic elastomers; they can be processed as thermoplastics at elevated temperature and act as vulcanized rubber at ambient temperatures ${ }^{2}$. From a practical point of view, these are widely applicable as nanocomposites, blend compatibilizers, toughening agents, for producing injection molded parts, medical devices and transparent packaging films ${ }^{5-9}$.

SBS triblock copolymers are non polar polymers but sometimes it is necessary to increase their functional properties by introducing polar groups ${ }^{10}$. One of the convenient ways of modifying the properties of styrene/diene based block copolymers is the selective epoxidation and subsequent sulfonation of the diene block thereby providing the opportunities to further functionalization of the copolymer domains. By controlling the degree of such chemical modifications, the functional properties of these materials may be controlled ${ }^{9-11}$.

\section{"Corresponding Author}


Several studies dealing with epoxidation of SBS and SIS triblocks can be found in literatures such as by Udipi ${ }^{12}$, Hsiue and Yang ${ }^{13}$, Jian and Hay ${ }^{14}$, Gregorio et al. ${ }^{15}$ and Margaritis et al. ${ }^{16}$. They have focused on the study of solubility parameter, glass transition temperature and activation energy for gas permeation through epoxidized membrane of the block copolymer. The epoxidation studies related to the addition of nucleophilic reagents such as acid, amine and alcohol onto epoxidized polydiene were performed by Soutif et $a l .{ }^{17}$, Jayawardana et $a l^{18}$ and Derouet et $a .^{19}{ }^{19}$ respectively. In addition, epoxidized styrene/butadiene block copolymers were used as templates for preparing nanostructured thermosets by Elena Serrano et al. ${ }^{20}$. Chaisuriyathepkul et al. ${ }^{21}$ synthesized acrylated block copolymer by the grafting reaction carried out through the ring opening addition of epoxidized SIS molecules. Weiss et $a l^{22}$ prepared ionomers from a sulfonated hydrogenated SBS triblock copolymer with acetyl sulfate in 1,2dichloroethane and studied their, water absorbancy as well as mechanical and thermal properties. Xie et $a .^{23}$ introduced sulfonic acid groups in order to prepare SBS ionomers by ring opening reaction of epoxidized SBS. They studied morphology as well as thermal and mechanical properties of the ionomers and their blends with polystyrene homopolymer.

The aim of present work is to study the effect of mid-block epoxidation of SBS triblock copolymers on their morphology and mechanical properties. In particular, structure properties correlation in a new kind of asymmetric SBS copolymer having a random polystyrene/polybutadiene (PS-co-PB) as middle rubbery block has been addressed in this work.

\section{Experimental Methods}

\section{Materials}

The polymer used in this work was polystyrene-block-polybutadiene-block-polystyrene (SBS) block copolymer with 74 wt.-\% PS and having weight average molecular weight $\left(\mathrm{M}_{\mathrm{w}}\right)$ of $127,300 \mathrm{~g} / \mathrm{mol}$ and polydispersity index of 1.10. The polymer was supplied by the BASF SE, Ludwigshafen, Germany. Toluene (99\%), formic acid (85\%), Polyethylene Glycol (PEG-400) and Hydrogen peroxide (30\%-w/v), Methanol (99.5\%) were purchased from local chemical supplier in Kathmandu and were used without further purification.

\section{Synthesis of epoxidized SBS (ESBS)}

The SBS block copolymer was epoxidized to different degrees following the standard procedures discussed in literature ${ }^{11-13,21}$. In a typical experiment, $5 \mathrm{~g}$ of the SBS sample was dissolved in $50 \mathrm{ml}$ of toluene in $250 \mathrm{ml}$ three necked round bottom flask equipped with a magnetic stirrer, thermometer and reflux condenser.
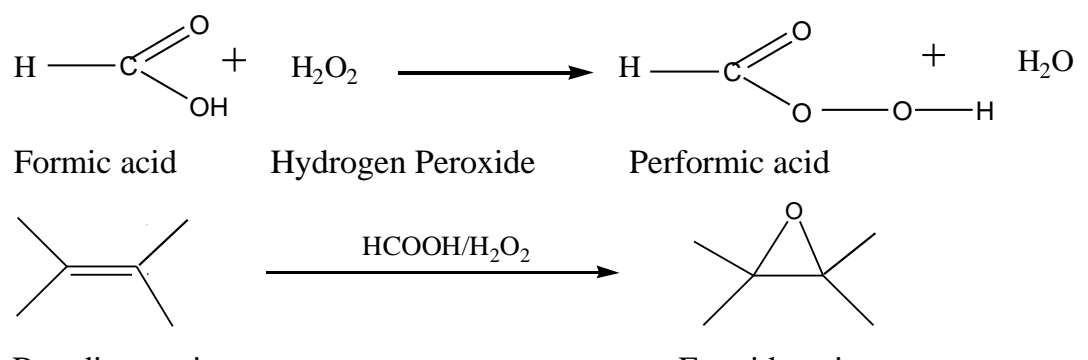

Butadiene unit

Epoxide unit

Scheme 1: Scheme of epoxidation reaction of styrene/butadiene block copolymer; the butadiene block undergoes chemical modification resulting in epoxide groups. 
Calculated amount of formic acid, hydrogen peroxide and two drops of PEG-400 (i.e. polyethylene glycol having average molecular weight of $400 \mathrm{~g} / \mathrm{mol}$ ) were added to the polymer solution and the performic acid was formed in situ by the reaction between hydrogen peroxide and formic acid. The solution was heated slowly to $60^{\circ} \mathrm{C}$ and stirred with magnetic stirrer for four hours after which heat was removed. The resulting modified polymer was coagulated by adding methanol. The residue was filtered and dried until constant weight. The epoxidation reaction is described in Scheme $1^{21}$.

The mass fraction of epoxy groups of epoxidized polystyrene-block-polybutadiene-block-polystyrene (ESBS) block copolymer was determined by directly titrating the $\mathrm{HCl}$-acetone (1:80 ratios by volume) solution of the polymer by standardized methanolic caustic soda solution following the procedure suggested by Xie et al. ${ }^{23}$ and Siggia et $a .^{24}$. The results are indexed in Table 1.

Table 1: Epoxy values of some of the epoxidized samples determined by titrimetrically

\begin{tabular}{lccc}
\hline $\begin{array}{l}\text { sample } \\
\text { designation }\end{array}$ & $\begin{array}{c}\text { targetted epoxidation } \\
(\text { wt.-\%) }\end{array}$ & $\begin{array}{c}\text { epoxy value } \\
(\mathrm{E})\end{array}$ & $\begin{array}{c}\text { experimental epoxidation } \\
(\text { wt.- } \%)\end{array}$ \\
\hline SBS & - & - & - \\
ESBS-10 & 10 & 0.074 & 7.4 \\
ESBS-20 & 20 & 0.142 & 14.2 \\
\hline
\end{tabular}

The epoxy value $(\mathrm{E})$ is calculated by the equation:

$$
\mathrm{E}=\left(\mathrm{V}_{0}-\mathrm{V}\right) \mathrm{xN} / 10 \mathrm{~W}
$$

where $\mathrm{V}_{0}, \mathrm{~V}$ and $\mathrm{N}$ are volume of alcoholic $\mathrm{NaOH}$ solution consumed by the blank polymer solution and the ESBS solution; and the strength of the alcoholic caustic soda solution expressed in normality. W is the weight of the ESBS sample in gram.

\section{Characterization techniques}

The structural characterization of the polymers was carried out by means of different techniques. Fourier transform infrared (FTIR) spectra were recorded on a Perkin Elmer FTIR Spectrometer using solution cast films in attenuated total reflection (ATR) mode. Morphological characterization was conducted with the aid of a transmission electron microscope (TEM, Leo 912, acceleration voltage 120 $\mathrm{V})$. Mechanical properties of the samples were evaluated by uniaxial tensile conducted in a Zwick universal tensile machine operated at $23{ }^{\circ} \mathrm{C}$ and cross head speed of $50 \mathrm{~mm} / \mathrm{min}$ using dog bone shaped specimens having gauge length of $50 \mathrm{~mm}$. Some samples were analyzed by differential scanning calorimeter (Perkin-Elmer DSC7) to determine the changes in glass transition temperatures.

\section{Results and Discussion}

The FTIR spectra of pure SBS and some of the ESBS samples are shown in Figure 1. Among various peaks observed in the spectra, it is interesting to carefully look at the peaks centered around $870 \mathrm{~cm}^{-1}$ and $1250 \mathrm{~cm}^{-1}$ which have been assigned to half of the epoxy group stretching and whole of the epoxy ring stretching respectively in the literature ${ }^{11,12,21}$. The presence of these peaks in our samples confirms the occurrence of epoxidation reaction. As expected, also the intensity of these peaks increases with increase in the degree of epoxidation implying the insertion of more and more epoxide groups to the doubly bonded $\mathrm{C}=\mathrm{C}$ locations in the butadiene rich chains.

The TEM result of pure SBS has been compared with that of an epoxidized sample in Fig. 2. The pure SBS triblock copolymer has well defined lamellar morphology (Figure 2, top) as also proved by 
earlier experiments on the sample prepared by different methods (solution casting, compression molding, injection molding etc $^{5}$. The average lamellar spacing is $30 \mathrm{~nm}$ with polystyrene lamellae being approximately $18 \mathrm{~nm}$ thick.

Upon epoxidation, the morphology of the SBS samples changes significantly (see Fig. 2, bottom). At $20 \%$ epoxidation, the lamellar morphology is maintained but remains largely distorted depicting the diffused phase boundary between the components. At high epoxidation content, the lamellar morphology was found to completely disappear leading to worm-like domains ${ }^{25}$. This observation suggests that the microphase separation behavior of the block copolymer is drastically altered by the insertion of epoxy groups into the butadiene chains. That the phase boundaries become more diffuse with increase in degree of epoxidation implies that the chemical modification changes the chemistry in such a way that the thermodynamic compatibility is enhanced by epoxidation.

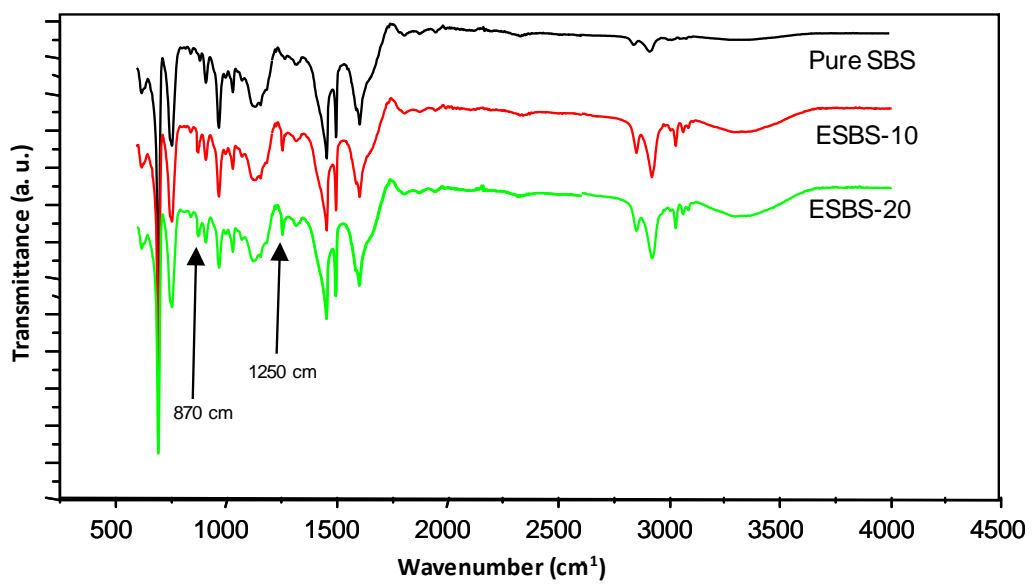

Figure 1: FTIR spectra of samples ESBS-10 and ESBS-20 compared with that of pure SBS
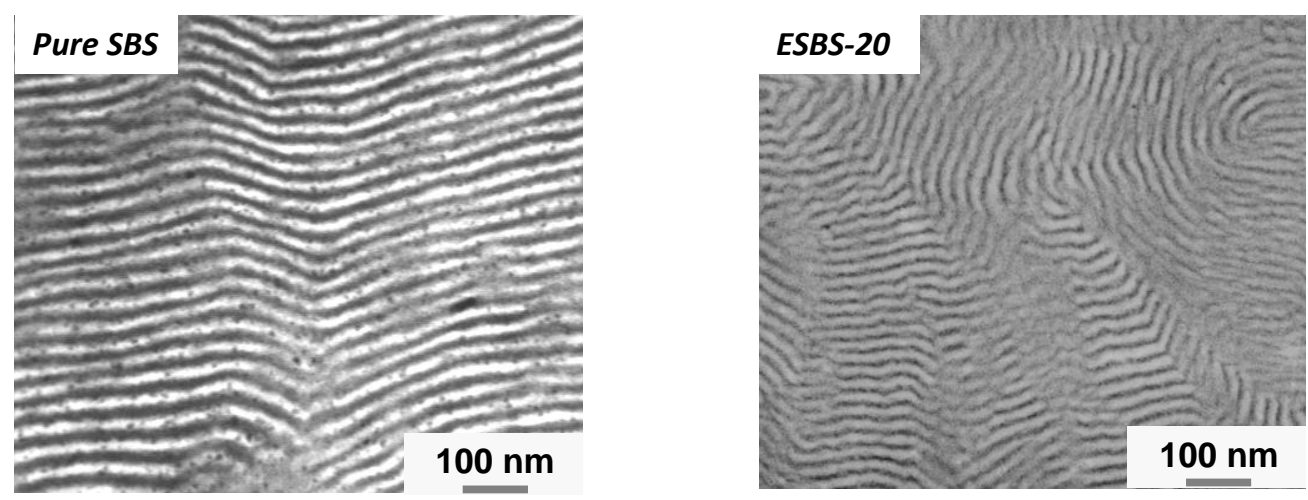

Figure 2: TEM images of pure SBS (left) and samples epoxidized to $20 \mathrm{wt}$-\% (right); butadiene-rich phase appears dark in the TEM images.

The change in microphase-separation behavior was also reflected in the fracture surface morphology of the samples using SEM analyses. While the fracture surface morphology of the pure SBS showed rough features comprising stretched fibrils typical of a ductile material the highly epoxidized sample 
which act as the cause of brittle and premature failure of the specimens ${ }^{25}$. Tensile stress-strain curves of epoxidized samples are compared with that of pure SBS copolymer in Fig. 3. The specimens were strained up to fracture. It can be seen that low degree of epoxidation (up to $10 \%$ ) leads to a slight improvement of mechanical properties in terms of the stress level of the sample. The strain at break is practically unaffected. Further epoxidation of the SBS causes progressive decrease in the elongation at break. In general, though small, there is a trend of the increase in the yield stress of the sample with epoxidation degree (see Fig. 3 and Table 2).

Table 2: Characteristic properties of the investigated samples.

\begin{tabular}{lcccc}
\hline Sample & $\mathrm{T}_{\mathrm{g} \text {-soft }}\left({ }^{\circ} \mathrm{C}\right)$ & $\mathrm{HV}(\mathrm{MPa})[25]$ & $\sigma_{\mathrm{Y}}(\mathrm{MPa})$ & $\mathrm{W}_{\mathrm{e}} / \mathrm{W}_{\mathrm{p}}[25]$ \\
\hline SBS & -50 & 21.2 & 8.5 & 0.79 \\
ESBS-10 & - & 33.7 & 10.0 & 0.59 \\
ESBS-20 & -32 & 45.0 & 12.5 & 0.39 \\
\hline
\end{tabular}

HV - Vicker's Hardness, $\sigma_{\mathrm{Y}}$ - yield stress, $\mathrm{W}_{\mathrm{e}} / \mathrm{W}_{\mathrm{p}}$ - ratio of elastic $\left(\mathrm{W}_{\mathrm{e}}\right)$ and plastic $\left(\mathrm{W}_{\mathrm{p}}\right)$ work of deformation; all the parameters except $\sigma_{\mathrm{Y}}$ were determined by microhardness measurements, $\mathrm{T}_{\mathrm{g}}$ was determined by DSC.
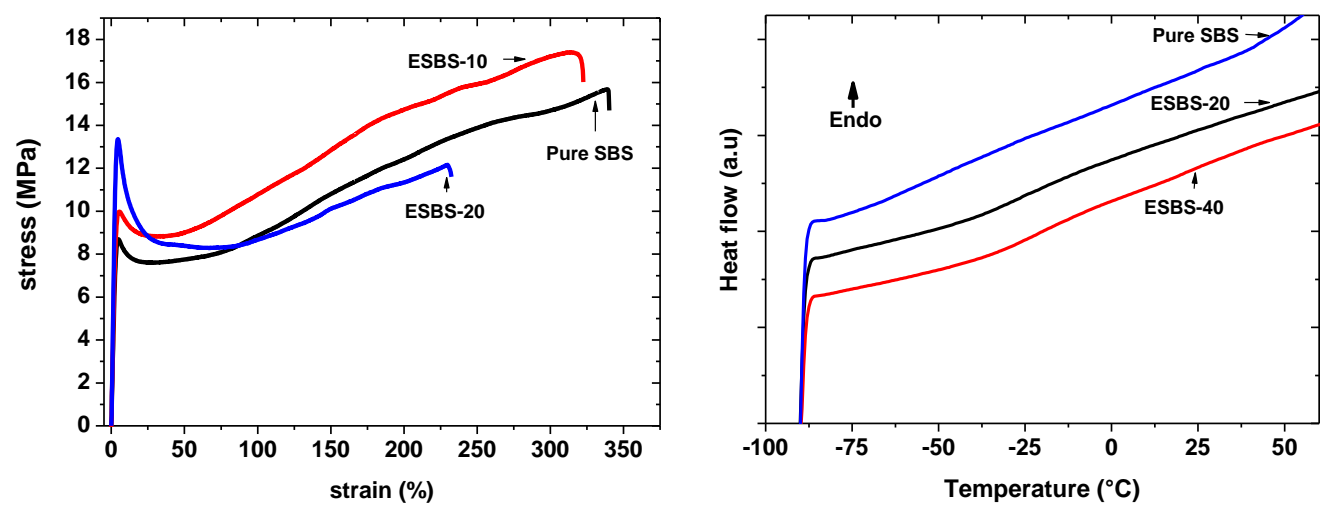

Figure 3 (left): Tensile stress-strain curves of SBS block copolymer compared with that of epoxidized samples. Figure 4 (right): DSC plots of SBS block copolymer compared with the epoxidized samples

Mechanical properties of the samples were evaluated also by recording microindentation tests. The details have been published in another pape ${ }^{25}$. In consistence with the results from the tensile testing, there is an increasing trend in Vickers hardness of the sample with the degree of epoxidation (see Table 2). At the same time, as expected the plasticity of the sample increase with increase in hardness which is manifested in the decrease in the elastic to plastic work of deformation $\left(\mathrm{W}_{\mathrm{e}} / \mathrm{W}_{\mathrm{p}}\right)$, Table 2.

The normalized DSC plots of some epoxidized samples are compared with that of pure SBS in Fig. 4 compare the glass transition of the soft butadiene rich phase which actually undergoes epoxidation reaction. The glass transition temperature of the hard phase (i.e. polystyrene) remains practically unchanged, and it has not been the object of discussion in this paper. The results are indexed also in Table 2.

The soft phase in the pure SBS has $\mathrm{T}_{\mathrm{g}}$ of $-50{ }^{\circ} \mathrm{C}$ while that of ESBS-20 and ESBS- 40 increase to -32 ${ }^{\circ} \mathrm{C}$ and $-22{ }^{\circ} \mathrm{C}$ respectively. Thus, at targeted epoxidation degree of $20 \%$, the glass transition temperature of the soft phase increased by some $20{ }^{\circ} \mathrm{C}$. Further increase in epoxidation to $40 \%$ increased the $\mathrm{T}_{\mathrm{g}}$ by another $10{ }^{\circ} \mathrm{C}$. These observations are in consistence with the increase in hardness and plasticity of the sample. 


\section{Conclusions}

An architecturally asymmetric SBS was successfully epoxidized to different extent and characterized by electron microscopy, infrared spectroscopy, differential scanning calorimetry and tensile testing. The results can be summarized as follows:

1. The microphase separation behavior of the block copolymer was found to be greatly influenced by the epoxidation of the rubbery block of the SBs block copolymer as shown by the TEM imaging.

2. At lower degree of epoxidation (up to $20 \%$ ), there was a slight increase in yield stress, hardness and plasticity of the samples. Parallel increase in yield stress and hardness with glass transition temperature of the soft phase was observed.

\section{Acknowledgements}

R. A. acknowledges research groups of Prof. G. H. Michler and Prof. W. Grellmann for providing necessary laboratory facilities to carry out a part of the work presented in this work. He further thanks Alexander von Humboldt $(\mathrm{AvH})$ Foundation for providing support during his research visits to Germany on different occasions. We thank BASF SE for the kind supply of SBS sample and Mrs. S. Goerliz (Halle), Mr. N. L. Bhandari and Mrs. J. Giri (Kathmandu) for technical supports.

\section{References}

1. I. W. Hamley, The Physics of Block Copolymers, Oxford Publishers, London, 1998.

2. G. Hoden, Understanding Thermoplastic Elastomers, Carl Hanser Verlag, Munich, 2001.

3. R. B. Grubbs, M. E. Broz, J. M. Dean and F. S. Bates, Macromoleules, 2000, 33, 2308.

4. M. Antonietti, S. Forster, J. Hartman and S. Oesteich, Macromoleules, 1996, 29, 3800.

5. R. Adhikari and G. H. Michler, Prog. Polym. Sci., 2004, 29, 949.

6. M. Chipara, D. Hui, J. Sankar, D. Leslie-Pelecky, A. Bender, L. Yue, R. Skomski and D. J. Sellmyer, Composites, 2004, 35, 235.

7. H. Q. Xie, Y. Chen, W. Yang and D. Xie, J. Appl. Polym. Sci., 2006, 99, 1975.

8. I. W. Hamley, Prog. Polym. Sci., 2009, 34, 1161.

9. R. T. Clay and R. E. Cohen, New J. Chem., 1998, 22, 745.

10. W. K. Hung, G. H. Hsiue and W. H. Hou, J. Polym. Sci.:Poly. Chem., 1988, 26, 1867.

11. H. Q. Li, X. R. Zeng and W. Wu, J. Elast. Plast., 2008, 40, 317.

12. K. Udipi, J. Appl. Polym. Sci., 1979, 23, 3301.

13. G. H. Hsiue and J. M. Yang, J. Polym. Sci. Part A: Poly. Chem., 1990, 28, 3761.

14. X. Jian and A. S. Hay, J. Polym. Sci. Part A: Poly. Chem., 1991, 29, 1183.

15. J. R. Gregorio, A. E. Gerbase, A. N. F. Mendes, P. D. Marcico and A. Rigo, React. Funct. Polym., 2005, 64, 83 .

16. A. G. Margaritis, J. K. Kallitsis and N. K. Kalfoglou, Polymer, 1989, 30, 2253.

17. J. C. Soutif, P. Klinpituksa and J. C. Brosse, Makromol. Chem., 1992, 193,315.

18. S. Jayawardena, D. Reyx, D. Durand and C. P. Pinazzi, Makromol. Chem. Rapid Communication, $1982, \mathbf{5}, 649$.

19. D. Derouet, J. C. Brosse and A. Challioui, E. Polym. J., 2001, 37, 1327.

20. E. Serrano, M. Larranaga, P. M. Remiro, I. Mondragon, P. M. Carrasco, J. A. Pomposo and D. Mecerreyes, Macromol. Chem. Phys., 2004, 205, 987.

21. A. Chaisuriyathepkul, P. Klinpituksa, P. Phinyocheep, C. Nakason and S. Kittipoon, e-Polymers, 2008, No: 141.

22. R. A. Weiss, S. Ashish, C. L. Willis, L. A. Pottick, Polymer, 1991, 32, 1867.

23. H. Q. Xie, W. G. Yu, G. Y. Liao, W. Yang and D. Xie, J. Elast. Plast., 2007, 39, 317.

24. S. Siggia, J. G. Hanna, Quantitative Organic Analysis via Functional Group, $4^{\text {th }}$ Edition, John Wiley \& Sons, New York, 1979.

25. R. Pandit, J. Giri, R. Lach, W. Grellmann, G. H. Michle, B. Youssef, J. M. Saiter and R. Adhikari, Macromol. Symp. 2012, in Press. 